\title{
High Blood Pressure and Stroke in the City of Lubumbashi: Determinants and Socio-Demographic Characteristics, Case of the Rail Ways Company Hospital
}

\author{
Luhanga mulumbati Onesiphore', Ilunga Kandolo Simon ${ }^{2 *}$, Kabamba wa Kabamba Christian³, \\ Sumba Chenge Louis ${ }^{1}$, Kabyla Ilunga Benjamin ${ }^{3}$, Kashindi Numbi Clément ${ }^{3}$ \\ ${ }^{1}$ Higher Institute of Statistics, Lubumbashi, Democratic Republic of Congo \\ ${ }^{2}$ Department of Health Education, School of Public Health, University of Lubumbashi, Lubumbashi, Democratic Republic of Congo \\ ${ }^{3}$ Faculty of Medicine, University of Lubumbashi, Lubumbashi, Democratic Republic of Congo \\ Email:*silungak@gmail.com
}

How to cite this paper: Onesiphore, L.M., Simon, I.K., Christian, K.K., Louis, S.C., Benjamin, K.I. and Clément, K.N. (2019) High Blood Pressure and Stroke in the City of Lubumbashi: Determinants and SocioDemographic Characteristics, Case of the Rail Ways Company Hospital. Open Access Library Journal, 6: e5985.

https://doi.org/10.4236/oalib.1105985

Received: December 9, 2019

Accepted: December 24, 2019

Published: December 27, 2019

Copyright $\odot 2019$ by author(s) and Open Access Library Inc.

This work is licensed under the Creative Commons Attribution International License (CC BY 4.0).

http://creativecommons.org/licenses/by/4.0/

\begin{abstract}
Introduction: We conducted a cross-sectional study to describe the epidemiological and sociodemographic situation of stroke and high blood pressure at the Lubumbashi rail ways company hospital. Methodology: Our cross-sectional analytical study is spread over a period of one year, from January 1st to December 31st, 2018. The study population is the one having suffered from high blood pressure and stroke at the Lubumbashi railways company hospital during our period. Our sampling is exhaustive and its size is 487 patients among 372 high blood pressure patients. The data were collected on Excel and analyzed on SPSS version 23. Results: The prevalence of high blood pressure is $76.4 \%$. The average age of hypertensives is $62.6 \pm 9.4$ years. The extreme ages are respectively 17 and 91 years. Women are the majority with $52.9 \%$. There is no statistically significant link between sexes, living in urban or rural areas, diabetes, or renal failure with the occurrence of high blood pressure at the Lubumbashi railways company hospital during our study period (P-value $>0.05)$. No statistically significant association was observed between vital records and arterial hypertension at the Lubumbashi railways company hospital during our study period ( $\mathrm{P}$-value $>0.05$ and Chi-square $<$ 3.84 ). The age of the patients was by no means associated with the occurrence of cerebrovascular accidents (Chi-square $<3.84$ and P-value $>0.05$ ). Living in an urban area (Chi-square: 5.02, P-value: 0.025) and kidney failure (Chi-square: 4.1, P-value: 0.04 ) predispose to accidents cerebrovascular disorders, whereas being diabetic does not predispose to stroke (Chi-square, 0.1, P-value: 0.7 ). Conclusion: High blood pressure remains a reality in our envi-
\end{abstract}


ronment. Special attention must be paid to this pathology that spares no one. The consequences inherent to this pathology (stroke, death and even disability) remain formidable.

\section{Subject Areas}

Emergency \& Critical Care, Surgery \& Surgical Specialties

\section{Keywords}

High Blood Pressure, Stroke, Determinants, Lubumbashi

\section{Introduction}

For, the World Bank, quoted by YAYEHD [1], the prevalence of high blood pressure (hypertension) in sub-Saharan Africa is increasing, a manifestation of a rapid epidemiological transition, and requires the mobilization of significant resources by these countries. The World Bank estimates that it is cheaper to prevent cardiovascular disease than to treat it, suggesting the need to know the importance of hypertension to enable the development of prevention programs in our populations.

Stroke and high blood pressure are the leading causes of death and disability worldwide. Although there is a lack of comprehensive data on stroke surveillance in Africa, available data indicate that the age-standardized mortality, number of cases, and prevalence of age-standardized disabling stroke are similar to or greater than those measured in most high-income regions of the United States In Africa, more than $90 \%$ of patients with haemorrhagic stroke and more than half with ischemic stroke have high blood pressure. However, awareness of hypertension and the prevention, treatment and control of hypertension remains very low in Africa, although recent surveys show an increasing prevalence of the disease, which is consistent with the nutritional and nutritional transition epidemiology in the region [2].

High blood pressure is a common, modifiable and inherited cardiovascular risk factor. Essential hypertension is a polygenic complex disease, in which many genes and environmental factors are involved. Recently, advances in the identification of genetic variants associated with blood pressure and essential hypertension have been made through extensive international studies on the entire human genome [3].

According to Donnison C., quoted by ATOBA, formerly unknown to African indigenous populations and long misunderstood among these populations, hypertension is nowadays a major public health problem in sub-Saharan Africa (SSA). Several epidemiological studies conducted around the world indicate that heredity, age, gender, place of residence, level of education, income, social burden, obesity, consumption of alcoholic beverages and tobacco, marital status, lack of exercise are non-biological factors frequently associated with hyperten- 
sion [4] [5].

Cardiovascular disease (CVD) is now a serious public health concern for developing countries (DCs) [6] [7]; they pose a serious threat to economic development, particularly because of the prohibitive costs of their long-term treatments and the negative effects of these diseases on productivity [8]; and they suffocate the health budgets of these nations with limited financial resources [9].

\section{Methodology}

The cross sectional study covers a period of one year, from January 1st to December 31st, 2018.

The study population is the one having suffered from arterial hypertension and having consulted at the Lubumbashi railway company hospital during our study period (from 01/01/2018 to 31/12/2018).

All high blood pressure patients who attended the Lubumbashi railway company hospital during our study period were included in this study.

The sampling is exhaustive and its size is 372 patients.

\section{Results}

The sex ratio is 0.948 ( 250 Females versus 237 Males) (Figure 1).

From the observation of Table 1, it appears that of those who were declared hypertensive 372 , ten died among hypertensives.

The average age of hypertensives is $62.6 \pm 9.4$ years. The extreme ages are respectively 17 and 91 years (Figure 2).

From the results of Table $2 \&$ Table 3 , it appears that there is no link between marital status and hypertension ( $\mathrm{P}$-value $>0.05$ ).

From the results in Table 4, it appears that there is no statistically significant association between cholesterol and stroke (P-value > 0.05). Of 372 diabetics, $6.7 \%$ developed a stroke.

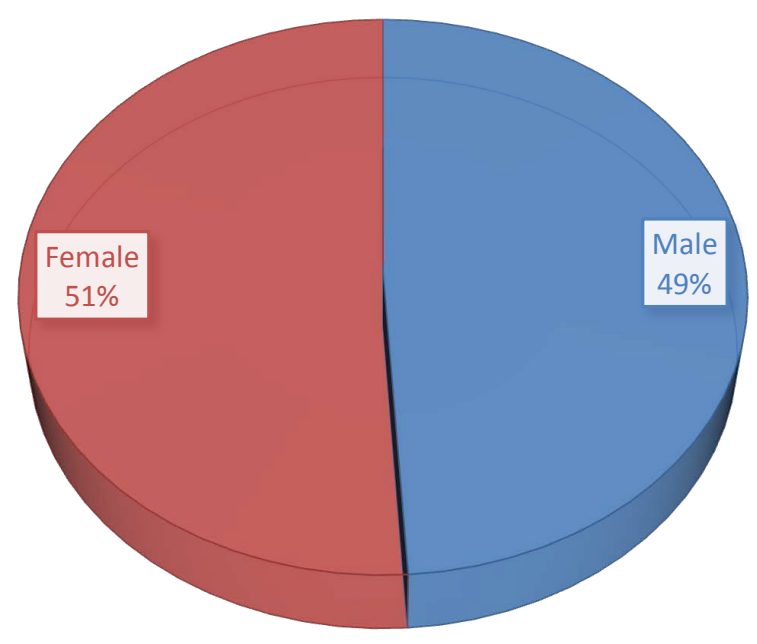

Figure 1. Distribution of patients by sex. 


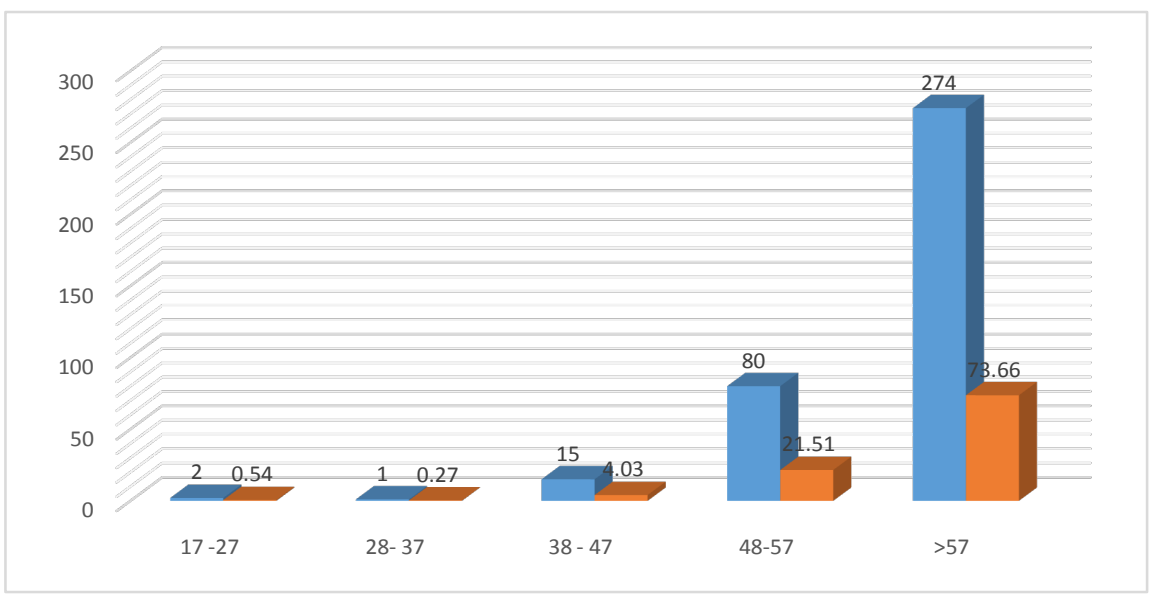

Figure 2. Distribution of hypertensive by age.

Table 1. Association between outcome and pathologies.

\begin{tabular}{|c|c|c|c|}
\hline \multirow[b]{2}{*}{ High Blood pressure } & \multicolumn{2}{|c|}{ STATUS } & \multirow{2}{*}{ Total } \\
\hline & deceased & recovered & \\
\hline Yes & 10 & 362 & 372 \\
\hline No & 1 & 114 & 115 \\
\hline Total & 11 & 476 & 487 \\
\hline
\end{tabular}

Table 2. Association between sex and hypertension.

\begin{tabular}{|c|c|c|c|c|}
\hline \multicolumn{5}{|c|}{ Hypertension } \\
\hline variable & YES $(N=372)$ & NO $(\mathrm{N}=115)$ & OR & IC95\% \\
\hline \multicolumn{5}{|l|}{ Sex } \\
\hline Male & 175 & 62 & 0.76 & {$[0.5-1.2]^{*}$} \\
\hline Female & 197 & 53 & & \\
\hline \multicolumn{5}{|c|}{ Urban area } \\
\hline Yes & 358 & 111 & 0.9 & {$[0.3-2.9]^{*}$} \\
\hline No & 14 & 4 & & \\
\hline \multicolumn{5}{|l|}{ Diabetes } \\
\hline Yes & 38 & 8 & & \\
\hline No & 334 & 107 & 1.5 & {$[0.7-3.4]^{*}$} \\
\hline \multicolumn{5}{|c|}{ Kidney insufficiency } \\
\hline Yes & 64 & 18 & 1.1 & {$[0.6-1.9]^{*}$} \\
\hline No & 308 & 97 & & \\
\hline
\end{tabular}

${ }^{\star}$ P-value $>0.05$.

It can be seen from Table 5 that there is no link between age and stroke (P-value $>0.05)$.

From the results in Table 6, it appears that there is no link between diabetes and stroke (P-value $>0.05)$ but the link is statistically significant between the urban environment and renal insufficiency. And stroke ( $\mathrm{P}$-value 0.025 and 0.04). 
Table 3. Association between marital status and hypertension.

\begin{tabular}{|c|c|c|c|c|c|}
\hline \multirow[b]{2}{*}{ Marital Status } & \multicolumn{2}{|c|}{ HIGH BLOOD PRESSURE } & \multirow{2}{*}{ Total } & \multirow[b]{2}{*}{ Chi-square } & \multirow[b]{2}{*}{$\mathrm{P}$-value } \\
\hline & YES & No & & & \\
\hline Single & 1 & 0 & 1 & 1.1 & 1 \\
\hline Married & 370 & 114 & 484 & & \\
\hline Widower & 1 & 1 & 2 & & \\
\hline TOTAL & 372 & 115 & 487 & & \\
\hline
\end{tabular}

Table 4. Association between cholesterol and stroke.

\begin{tabular}{ccccc}
\hline \multicolumn{5}{c}{ STROKE } \\
Cholesterol & YES & NO & Chi-square & P-value \\
\hline$<200 \mathrm{mg} / \mathrm{dl}$ & 14 & 182 & 1.4 & 0.5 \\
$>240 \mathrm{mg} / \mathrm{dl}$ & 3 & 75 & & \\
$200-239 \mathrm{mg} / \mathrm{dl}$ & 8 & 90 & & \\
Total & 25 & 347 & & \\
\hline
\end{tabular}

Table 5. Association between age and stroke.

\begin{tabular}{ccccc}
\hline & \multicolumn{2}{c}{ STROKE } & & \\
\hline Age & Yes & No & Chi-square & P-value \\
\hline $17-27$ & 0 & 2 & 2.5 & 0.6 \\
$28-37$ & 0 & 1 & & \\
$38-47$ & 2 & 13 & & \\
$48-57$ & 3 & 77 & & \\
$>57$ & 20 & 254 & & \\
Total & 25 & 347 & & \\
\hline
\end{tabular}

Table 6. Association between variables and stroke.

\begin{tabular}{|c|c|c|c|c|}
\hline \multicolumn{5}{|c|}{ Stroke } \\
\hline Variables & Yes $(\mathrm{N}=25)$ & No $(\mathrm{N}=347)$ & Chi-square & P-valeur \\
\hline \multicolumn{5}{|l|}{ Urban } \\
\hline Yes & 22 & 336 & 5.02 & $\underline{0.025^{*}}$ \\
\hline No & 3 & 11 & & \\
\hline \multicolumn{5}{|l|}{ Diabetes } \\
\hline Yes & 2 & 36 & 0.1 & 0.7 \\
\hline No & 23 & 311 & & \\
\hline \multicolumn{5}{|c|}{ Kidney failure } \\
\hline Yes & 8 & 56 & 4.1 & $\underline{0.04^{*}}$ \\
\hline No & 17 & 291 & & \\
\hline
\end{tabular}

${ }^{*}$ P-value $<0.05$. 


\section{Discussion}

The sex ratio is 0.948 (95 men for every 100 women and $51 \%$ for women), the majority of whom are affected as shown in Figure 1.

In our series, 11 deaths were observed out of a total of 487 patients, of whom $10(90.9 \%)$ were attributable to hypertension; thus, the lethality associated with arterial hypertension is $2.7 \%$ (Table 1 ).

Table 2 shows that the prevalence of arterial hypertension is $76.4 \%$. Our observation is different from that found by Egion in Nigeria where the $\mathrm{c}$ prevalence of hypertension was $18.3 \%$ (95\% CI $516.0 \%$ to $20.7 \%$ ). [10]. There is no link between marital status and HTA (P-value $>0.05)$. In Nigeria, high blood pressure was higher among married people (RR5.35, P5.00) [10].

There is no statistically significant relationship between sexes, whether living in urban or rural areas, diabetes, or kidney failure with the occurrence of high blood pressure at the Lubumbashi railways during our study period (P-value $>$ 0.05).

Barbet has, in his study revealed that high blood pressure is associated in 23.2\% of cases with heart disease [11]. The National Kidney Foundation attests that hypertension is one of the leading causes of chronic kidney disease. Over time, hypertension can damage blood vessels throughout your body. This can decrease the vital blood supply for important organs such as the kidneys. According to the same association, hypertension can also become a complication of chronic kidney disease. The kidneys play a key role in keeping the blood pressure within an acceptable range. Sick kidneys are less able to help regulate blood pressure. As a result, the tension increases [12].

Cholesterol levels (normal, moderate, or high) were not statistically significant to the occurrence of stroke ( $\mathrm{P}$-value $>0.05$ and Chi-square $<3.84$ ).

Table 4 indicates that the age of the patients was by no means associated with the occurrence of cerebrovascular accidents (Chi-square $<3.84$ and P-value $>$ 0.05).

Living in an urban area (Chi-square: 5.02, P-value: 0.025$)$ and kidney failure (Chi-square: 4.1, P-value: 0.04 ) predispose to accidents cerebrovascular disease, as shown in Table 6 (Chi-square, 0.1, P-value: 0.7). Recently, several studies have shown that chronic renal disease is associated with a risk of stroke [13]. Ousmane says that blood sugar and lipid disorders are very often associated with stroke [14].

For Thierry, the relative risk of stroke in diabetic patients compared to the non-diabetic population is 2.28 (95\% CI: 1.93 - 2.69) in women, and 1.83 (1.60 2.08) for men [15].

A cohort performed on 492 diabetic in Congolese hypertensives from Kinshasa until the onset of stroke or not indicates that $16.5 \%$ had presented the stroke. The rate of stroke is high in hypertensive diabetics with a relative risk of 6.2 (95\% CI 3.2 to 11.9, $\mathrm{P}<0.0001$ ) [16]. This proportion of hypertensives who have developed a stroke is close to ours $6.7 \%$. MILL in his study found that the risk factors for stroke are: high blood pressure (the main risk factor for stroke, 
ischemic or hemorrhagic with a relative risk of about 4); tobacco: $R R=2$; diabetes it presents a relative risk of 1.5 [17].

Regarding the link between place of residence and the occurrence of strokes, our results corroborate those in South Kivu where a higher prevalence of arterial hypertension $(\mathrm{P}<0.001)$ was observed in urban subjects than in rural subjects. hypertension (41.4\% vs $38.1 \%)$ [18].

\section{Conclusions}

High blood pressure remains a real public health problem today. Its prevalence is still worrying in all parts of the world.

We conducted a cross-sectional study of hypertension. The prevalence of high blood pressure is $76.4 \%$. Women are the most affected. The age of the patients was by no means associated with the occurrence of cerebrovascular accidents (Chi-square $<3.84$ and P-value $>0.05$ ). Cholesterol levels (normal, moderate, or elevated) were not statistically significant to the occurrence of stroke (P-value $>$ 0.05 and Chi-square $<3.84$ ).

\section{Conflicts of Interest}

The authors declare no conflicts of interest regarding the publication of this paper.

\section{References}

[1] Komlavi, Y., et al. (2013) Prévalence de l'hypertension artérielle et description de ses facteurs de risque à Lomé (Togo): Résultats d'un dépistage réalisé dans la population générale en mai.... Annales de Cardiologie et d Angéiologie (Paris), 62, 43-50. https://doi.org/10.1016/j.ancard.2012.09.006

[2] CDC-ATLANTA (2017) Centre national de prévention et de promotion de la santé, Centres de contrôle et de prévention des maladies, Mailstop.

[3] Bochud, M. and Burnier, M. (2009) Génétique et hypertension artérielle: Qu' avons nous-appris? Révue Médicale Suisse, 6.

[4] Addo, J., Smeeth, L. and Leon, D. (2007) Hypertension in Sub-Saharan Africa: A Systematic Review. Hypertension, 50, 1012-1018. https://doi.org/10.1161/HYPERTENSIONAHA.107.093336

[5] Kayima, J., Wanyenze, R.K., Katamba, A., Leontsini, E. and Nuwaha, F. (2013) Hypertension Awareness, Treatment and Control in Africa: A Systematic Review. BMC Cardiovascular Disorders, 13, 54. https://doi.org/10.1186/1471-2261-13-54

[6] Yach, D., Hawkes, C., Gould, C. and Hofman, K. (2004) The Global Burden of Chronic Diseases: Overcoming Impediments to Prevention and Control. JAMA, 291, 2616-2622. https://doi.org/10.1001/jama.291.21.2616

[7] Lopez, A., Mathers, C., Ezzati, M., Jamison, D. and Murray, C. (2006) Global and Regional Burden of Disease and Risk Factors, 2001: Systematic Analysis of Population Health Data. The Lancet, 367, 1747-1757. https://doi.org/10.1016/S0140-6736(06)68770-9

[8] Bloom, D., Cafiero, E., Jané-Llopis, E., Abrahams-Gessel, S., Bloom, L. and Murray, C.J.L. (2011) The Global Economic Burden of Non-Communicable Diseases. Geneva. 
[9] Mathers, C.D. and Loncar, D. (2006) Projections of Global Mortality and Burden of Disease from 2002 to 2030. PLOS Medicine, 3, 2011-2030. https://doi.org/10.1371/journal.pmed.0030442

[10] Egion, N.I.D.E.R., Igeria, N., Onwuchekwa, A.C., Mezie-okoye, M.M. and Babatunde, S. (2012) Prevalence of Hypertension in Kegbara-Dere: A Rural Community in the Niger Delta Region, Nigeria. Ethnicity \& Disease, 22, 7.

[11] Barbet, C. (2013) HTA d'origine rénale parenchymateuse. American Journal of Hypertension, 26, 1.

[12] N. Kidney Foundation (2007) Hypertension et maladie rénale chronique.

[13] Yacouba, N. (2018) L'insuffisance rénale chronique est-elle un facteur de risque d'accident vasculaire cérébral? Revista de Neurología (Paris), 174, S175-S176. https://doi.org/10.1016/j.neurol.2018.02.044

[14] Ousmane, C., et al. (2016) Lipid and Glucose Profile in Patients with Ischemic Cerebrovascular Accidents in Dakar. Pan African Medical Journal, 25, 29. https://doi.org/10.11604/pamj.2016.25.29.8906

[15] Thierry, F. and Jean, P. (2014) Diabète et accident vasculaire cérébral: Hommes et femmes inégaux devant le risque! Revue Médicale Suisse, 10, 837-837.

[16] Longo-Mbenza, B.B., Mombo Ngimbi, R., Ngoma, V., Mbungu-Fuele, C. and Buassa-bu-Tsumbu, B. (2007) Facteurs de risque d'accident vasculaire cérébral chez les diabétiques hypertendus noirs congolais de type 2. Annales de Cardiologie et d'Angéiologie (Paris), 57, 37-43. https://doi.org/10.1016/j.ancard.2007.08.013

[17] Moulin, T. (2005) Les accidents vasculaires cérébraux: Épidémiologie, physiopathologie des accidents vasculaires cérébraux ischémiques. Journal des Maladies Vasculaires, 30, 5-6. https://doi.org/10.1016/S0398-0499(05)74793-4

[18] Philippe, B., Katchunga, B., et al. (2017) Hypertension artérielle chez l'adulte Congolais du Sud Kivu: Résultats de l'étude Vitaraa. La Presse Médicale, 40, e315-e323. https://doi.org/10.1016/j.lpm.2010.10.036 